\section{Kidney Blood Pressure Research}

\title{
New Factors Predicting Delayed Graft Function: a Multi-Center Cohort Study of Kidney Donation After Brain Death Followed by Circulatory Death
}

\author{
Qipeng Sun ${ }^{\mathrm{a}}$ Zhengyu Huang ${ }^{\mathrm{a}}$ Honglan Zhou $^{\mathrm{b}}$ Minzhuan Linc Xuefeng Hua ${ }^{\mathrm{a}}$ \\ Liangqing Hong ${ }^{a}$ Ning Na ${ }^{a}$ Ruiming Caic Gang Wang ${ }^{b}$ Qiquan Sun ${ }^{a}$ \\ aDepartment of Renal Transplantation, The Third Affiliated Hospital, Sun Yat-sen University, Guangzhou, \\ ${ }^{b}$ Department of Urology, The First Affiliated Hospital, Jilin University, Changchun, 'Department of Renal \\ Transplantation, The Third Affiliated Hospital, Guangzhou Medical University, Guangzhou, China
}

\section{Key Words}

Donation after brain death followed by circulatory death (DBCD) - Kidney transplantation • Delayed graft function (DGF) • Risk factors

\begin{abstract}
Background/Aims: Delayed graft function (DGF) is a common complication following kidney transplantation adversely affecting graft outcomes. Donation after brain death followed by circulatory death (DBCD), a novel donation pattern, is expected to correlate with high incidence of DGF. However, little information is available about factors associated with DGF in DBCD. Methods: A total of 383 kidney transplants from DBCD donation in three institutions were enrolled. Associations of DGF with the clinical characteristics of recipients and donors were quantified. Results: In this retrospective multi-center study, the incidence of DGF was $19.3 \%$. Lower incidence of DGF was found in recipients for whom antithymocyte globulin was used for induction $(p<0.05)$, which was an independent protective factor against DGF (odds ratio $[\mathrm{OR}]=0.48 ; 95 \% \mathrm{CI} 0.27-0.86$ ). Two novel explicative variables were recognized as independent risk factors, including use of vasoactive drugs (OR $=3.15 ; 95 \% \mathrm{CI} 1.39-7.14)$ and cardiopulmonary resuscitation (OR $=2.51 ; 95 \% \mathrm{CI} 1.05-6.00)$, which contributed significantly to increased risk of DGF ( $p<0.05)$. Prolonged warm ischemia time (>18 min; OR $=2.42 ; 95 \%$ CI 1.36-4.32), was also predictive of DGF in DBCD. A prediction model was developed and achieved an area under the curve of 0.89 in predicting DGF when combined with reported parameters. Conclusion: The novel factors, confirmed for the first time in our study, will help to improve risk prediction of DGF and to determine optimal interventions to prevent DGF in clinical practice.




\section{Kidney Blood Pressure Research}

Sun et al.: Predicting DGF in DBCD

\section{Introduction}

Kidney transplantation is currently the preferred treatment modality for patients with end-stage renal disease [1]. With more widespread use of donors from donation after circulatory death (DCD), the incidence of delayed graft function (DGF) has increased and has become a common complication in kidney transplantation adversely impacting graft outcomes [2,3]. Many parameters, such as donor age, donor weight, peak panel reactive antibody (PRA) and cold ischemia time (CIT), as well as biomarkers were used to assess the possibility of DGF [4-7].

A novel donation concept, organ donation after brain death followed by circulatory death (DBCD), was officially initiated in China in 2011, and could be regarded as a combination of Maastricht donation types 3 and 4 [8-11]. Despite a planned protocol for mechanical support and subsequent implementation of cardiac death protocols after brain death, the new donation pattern was also expected to be associated with a high risk of DGF because it involves additional warm ischemia time (WIT) [10,11]. However, little information is available about the factors associated with DGF in DBCD donation.

We therefore carried out this multi-center cohort study involving 383 renal transplant recipients from DBCD to explore factors influencing DGF. Our aim was to identify new factors associated with DGF in DBCD donation which could contribute to improving current risk prediction in DGF and determining optimal interventions to prevent DGF.

\section{Materials and Methods}

\section{Study Population}

A multi-center, retrospective, observational cohort study was carried out involving 383 kidney transplants from DBCD performed from February 2012 to December 2015. The transplants were performed in three kidney transplant institutions: The Third Affiliated Hospital of Sun Yat-sen University, The First Affiliated Hospital of Jilin University, and The Third Affiliated Hospital of Guangzhou Medical University.

All the donors meet the eligibility criteria as follows: confirmed patient identity; age $\leq 65$ years; no history of kidney disease, drug abuse, or uncontrollable psychotic symptoms; no active infection including HIV, bacteria, or fungus; no history of uncontrolled hypertension or diabetes mellitus with complications; and no history of malignant melanoma, or metastatic or incurable malignancy [10].

No organs from executed prisoners were used in the study, and procurement of kidneys from all donors was conducted in accordance with the Declaration of Helsinki and the Declaration of Istanbul on Organ Trafficking and Transplant Tourism and approved by the Human Organ Transplantation and Ethic Committee of each institution. Donors' families determined the donation type voluntarily. The Ethics Committees were established according to the Operational Guidelines for Ethics Committees That Review Biomedical Research developed by the World Health Organization, and included physicians, lawyers, statisticians, paramedical personnel, and laypersons [12]. Organs were allocated according to medical urgency and the waiting time of patients on the list, which was coordinated by the China Organ Transplant Response System equitably and transparently [8].

The definition of brain death was strictly determined by the exclusion of confounders, as well as the presence of three essential findings, namely, irreversible coma, absence of spontaneous motor activity, and absence of all brain-stem reflexes. All three of the above requirements must be satisfied in clinical examinations, and at least two of three confirmatory laboratory test requirements should be satisfied according to the National Guidelines for Donation after Cardiac Death in China [10]. To determine the cessation of respiratory function, an apnea test should be carried out before declaration of brain death as follows: after mechanical ventilation and vasopressors withdrawn, $100 \% \mathrm{O}_{2}$ at a flow rate of $6 \mathrm{~L} / \mathrm{min}$ was administered to the patient via tracheal intubation for 8-10 min. Breathing movements should be closely observed and arterial blood gas analysis should be performed finally. Cessation of spontaneous respiratory 


\section{Kidney Blood Pressure Research}

function was defined as no breathing movement with $\mathrm{PaCO}_{2}$ equal or greater than $60 \mathrm{mmHg}$ or a rise of 20 $\mathrm{mmHg}$ more than basal level. Brain death of each donor was adjudicated independently by two neurologists or neurosurgeons $[10,13]$.

Cardiac death was legally defined as irreversible cessation of circulatory function, based on definitive proof by confirmatory tests, such as electrocardiography, intra-arterial monitoring, or Doppler ultrasound. An observation period of 5 min was also employed, prior to confirmation of death, to ensure the irreversibility and permanence of cardiac death [10].

\section{Organ Procurement and Management}

Organ donation and recovery were coordinated by an organ procurement organization established by the National Health and Family Planning Commission of China. For DBCD donors, following determination of brain death, written consent was obtained for donation of the kidney and withdrawal of life support. The obtained consent for donation was then reported to the organ donation committee, which supervised the process of DBCD.

Donors were monitored with invasive blood pressure sensors in the operating room. Following condolences, mechanical ventilation and vasopressors were withdrawn, and vital signs continued to be monitored. The definition of cardiac death was determined according to the aforementioned criteria, and after 5 min of observation following cardiac arrest, death was declared, and organ recovery initiated. According to the national guidelines in China, WIT was recorded from the termination of life support to the hypothermic perfusion of the graft, and CIT was recorded as the duration from hypothermic perfusion to blood reperfusion during transplantation surgery. The WIT of the kidney grafts was limited to less than $60 \mathrm{~min}$ [10]. Zero-time biopsies were also performed when deemed necessary.

\section{Immunosuppressive Regimen}

Either rabbit antithymocyte globulin (ATG) or anti-interleukin-2 receptor antibody (basiliximab) was administered as induction therapy. Additionally, methylprednisolone (500 mg/day) was continuously administered intravenously during the first 3 days postoperatively. Maintenance immunosuppressive regimens consisted of a calcineurin inhibitor, mycophenolate mofetil, and prednisone. Mycophenolate mofetil was initiated immediately after transplantation and maintained at a daily dose of 1.0-1.5 g. Tacrolimus or cyclosporine was started on Days $2-4$ at $0.1-0.15 \mathrm{mg} / \mathrm{kg} /$ day or $6-8 \mathrm{mg} / \mathrm{kg} / \mathrm{day}$, respectively, according to the level of recovery of renal graft function. The immunosuppressive regimens were adjusted to achieve target therapeutic trough levels in peripheral blood. Oral administration of prednisone, initiated at $30 \mathrm{mg}$ /day on Day 4 following transplantation, was reduced by $5 \mathrm{mg}$ every week to a maintenance dose of $10-15 \mathrm{mg} /$ day.

\section{Data Collection}

Baseline clinical demographics of donors were documented, including age, sex, body mass index, medical history, terminal serum creatinine, cause of death, intensive care unit time, WIT, CIT, use of vasoactive drugs, and CPR. Recipient variables included age, sex, preoperative serum creatinine, human leucocyte antigen (HLA) mismatches, PRA, duration of dialysis, and history of previous transplant. HLA mismatching between donor and recipient was categorized according to differences at the HLA-A, HLA-B, and HLA-DR loci, with 0-1 of 6 possible mismatches categorized as level 1, 2-4 mismatches as level 2, and 5-6 as level 3 [14]. Positive PRA was defined as peak PRA $>10 \%$ in our study.

The definition of DGF in our study is the use of dialysis in the first postoperative week, or failure of serum creatinine to decrease by $10 \%$ in the first $48 \mathrm{~h}$ following transplantation [15].

\section{Statistical Analysis}

Differences in clinical characteristics of recipients and donors in DBCD were examined using the t-test for continuous variables or the Chi-squared test for discrete variables. $P$-values were derived from likelihood ratio tests. Risk factors for DGF were evaluated using a multivariable binary logistic regression modeling technique.

Predictive accuracy of risk factors was assessed using the receiver operating curve (ROC) of a plot of sensitivity versus 1-specificity for different threshold probabilities of DGF. The threshold probabilities were 


\section{Kidney \\ Blood Pressure Research}

Kidney Blood Press Res 2018;43:893-903

\begin{tabular}{l|l}
\hline DOI: $10.1159 / 000490337$ & (C) 2018 The Author(s). Published by S. Karger AG, Basel
\end{tabular}

Published online: 5 June, 2018 www.karger.com/kb

Sun et al.: Predicting DGF in DBCD

arbitrary cut points used to classify patients as DGF and non-DGF.

After developing the logistic regression model, independent data from 38 recipients were used to validate the clinical value of this model. Missing data were assumed to be missing completely at random, and incomplete data entries were not included in our analyses. To compare the clinical value of this developed model, we also used the web-based DGF risk calculator developed by Irish et al. (www.transplantcalculator. com/DGF) to obtain a predicted probability of developing DGF [4]. The areas under the ROCs (AUCs) were compared using the method of DeLong et al. [16].

All analyses were performed with Statistical Package for Social Science 22.0 for Windows (IBM Corp., Armonk, NY). A value of $p<0.05$ was considered as statistical significance.

\section{Results}

\section{Donor and Recipient Characteristics}

Qualitative and quantitative variables were described for 199 donors and 383 recipients of DBCD in Tables 1 and 2. For donors, mean age was $40.4 \pm 13.0$ years with $61.3 \%$ older than 40 years, and $84.9 \%$ were men. The most frequent cause of death was head trauma (53.3\%), followed by cerebrovascular accident (42.2\%) and others (4.5\%); $21.6 \%$ of the donors had a history of hypertension, and $6 \%$ had diabetes or heart disease. In $76.9 \%$ of the donors, vasoactive drugs were used before organ procurement .8.5\% of donors had received CPR. Terminal serum creatinine was $149.9 \pm 55.9 \mu \mathrm{mol} / \mathrm{L}$. Mean duration of CIT and WIT was $5.5 \pm 2.2 \mathrm{~h}$ and $16.2 \pm 5.2 \mathrm{~min}$, respectively.

For recipients, mean age was $42.5 \pm 11.1$ years and $62.4 \%$ were men; $97.7 \%$ were recipients of first transplants, and only $2.3 \%$ had previous transplantation. The mean preoperative serum creatinine level was $931.2 \pm 287 \mu \mathrm{mol} / \mathrm{L}$, with a mean dialysis duration of $1.3 \pm 1.0$ years. PRA was positive in 12 (3.1\%) recipients and 274 recipients had $0-1$ of 6 possible mismatches at the HLA-A, -B, and -DR loci. Use of ATG as induction therapy was more common than use of anti-interleukin- 2 receptor antibody ( $76 \%$ with ATG vs. $24 \%$ with anti-interleukin-2 receptor antibody, $\mathrm{p}<0.05$ ).

\section{Donor and Recipient Characteristics Related to DGF}

As shown in Tables 1 and 2,19.3\% of recipients developed DGF 1 week postoperatively. Donors using vasoactive drugs were more likely to develop DGF compared with those who did not use vasoactive drugs $(22.9 \%$ vs. $8.7 \%, \mathrm{p}=0.035)$. Donors with a history of CPR had a higher incidence of DGF (47.0\% in CPR vs. $17.0 \%$ in no CPR, $p=0.007)$. According to a previous published study, WIT was divided into two groups: $\geq 18 \mathrm{~min}$ and $>18 \mathrm{~min}$ [17]. In WIT $>18 \mathrm{~min}, 31.5 \%$ had developed DGF compared with $15.2 \%$ in WIT $\leq 18 \mathrm{~min}(\mathrm{p}=0.015)$. In recipients, patients with ATG as induction therapy had significantly lower incidence of DGF compared with anti-interleukin-2 receptor antibody (8.6\% in ATG vs. 53.3\% in antiinterleukin-2 receptor antibody, $\mathrm{p}<0.05$ ).

A matched group in which paired recipients received graft donations from the same donors was investigated (Table 3). Based on their induction therapies, 50 recipients who received graft donations from the same donors were screened out and divided into an ATG group $(n=25)$ and an anti-interleukin-2 receptor antibody group $(n=25)$. Patients who received ATG had significantly lower incidence of DGF compared with those who received anti-interleukin-2 receptor antibody ( $4.0 \%$ vs. $36.0 \%, \mathrm{p}=0.005)$.

\section{Predictive Model Development and Validation}

Predictive factors for DGF were studied using a multivariable binary logistic regression modeling technique. The results of the final model are presented in Table 4. The four most significant factors associated with DGF were use of vasoactive drugs (odds ratio [OR] yes vs. no $=3.15 ; 95 \% \mathrm{CI}=1.39-7.14$ ), $\mathrm{CPR}$ (OR yes vs. no $=2.51 ; 95 \% \mathrm{CI}=1.05-6.00)$, ATG used as induction therapy (OR yes vs. no $=0.48 ; 95 \% \mathrm{CI}=0.27-0.86$ ), and WIT group (OR $>18 \mathrm{~min}$ 


\section{Kidney Blood Pressure Research}

Table 1. Donor characteristics at time of transplantation stratified by DGF. ICU, intensive care unit; BMI, body mass index; Cr, creatinine; DGF, delayed graft function

\begin{tabular}{|c|c|c|c|c|}
\hline Donor characteristics & All patients, n (\%) & DGF, n (\%) & No DGF, n (\%) & p-value \\
\hline Total & 199 & 39 & 160 & \multirow{7}{*}{0.398} \\
\hline Age (years) & $40.4 \pm 13.0$ & - & - & \\
\hline$<30$ & $44(22.1)$ & $10(25.6)$ & $34(21.3)$ & \\
\hline $30-39$ & $33(16.6)$ & $4(10.3)$ & $29(18.1)$ & \\
\hline $40-49$ & $71(35.7)$ & $18(46.2)$ & $53(33.1)$ & \\
\hline $50-59$ & $43(21.6)$ & $6(15.4)$ & $37(23.1)$ & \\
\hline$>59$ & $8(4.0)$ & $1(2.5)$ & $7(4.4)$ & \\
\hline \multicolumn{5}{|l|}{ Sex } \\
\hline Male & $169(84.9)$ & $37(94.9)$ & $132(82.5)$ & \multirow{2}{*}{0.077} \\
\hline Female & $30(15.1)$ & $2(5.1)$ & $28(17.5)$ & \\
\hline Body mass index $\left(\mathrm{kg} / \mathrm{m}^{2}\right)$ & $22.9 \pm 2.2$ & - & - & \multirow{5}{*}{0.452} \\
\hline$<20$ & $20(10.1)$ & $4(10.3)$ & $16(10.0)$ & \\
\hline $20-24.9$ & $152(76.4)$ & $27(69.1)$ & $125(78.1)$ & \\
\hline $25-29.9$ & $26(13.1)$ & $8(20.6)$ & $18(11.3)$ & \\
\hline$>30$ & $1(0.4)$ & $0(0)$ & $1(0.6)$ & \\
\hline \multicolumn{5}{|c|}{ Terminal serum creatinine $(\mu \mathrm{mol} / \mathrm{L})$} \\
\hline$>133$ & $84(42.2)$ & $20(51.3)$ & $64(40.0)$ & \multirow{2}{*}{0.211} \\
\hline$\leq 133$ & $115(57.8)$ & $19(48.7)$ & $96(60.0)$ & \\
\hline \multicolumn{5}{|l|}{ Cause of death } \\
\hline Cerebrovascular accident & $84(42.2)$ & $17(43.6)$ & $67(41.9)$ & \multirow{3}{*}{0.804} \\
\hline Head trauma & $106(53.3)$ & $21(53.8)$ & $85(53.1)$ & \\
\hline Other & $9(4.5)$ & $1(2.6)$ & $8(5.0)$ & \\
\hline \multicolumn{5}{|l|}{ Hypertension } \\
\hline Yes & $43(21.6)$ & $7(17.9)$ & $36(22.5)$ & \multirow{2}{*}{0.666} \\
\hline No & $156(78.4)$ & $32(82.1)$ & $124(77.5)$ & \\
\hline \multicolumn{5}{|l|}{ Heart disease } \\
\hline Yes & $6(3.0)$ & $2(5.1)$ & $4(2.5)$ & \multirow{2}{*}{0.335} \\
\hline No & $193(97.0)$ & $37(94.9)$ & $156(97.5)$ & \\
\hline \multicolumn{5}{|l|}{ Diabetes } \\
\hline Yes & $6(3.0)$ & $1(2.6)$ & $5(3.1)$ & \multirow{2}{*}{1} \\
\hline No & $193(97.0)$ & $38(97.4)$ & $155(96.9)$ & \\
\hline \multicolumn{5}{|l|}{ Use of vasoactive drugs } \\
\hline Yes & $153(76.9)$ & $35(89.7)$ & $118(93.8)$ & \multirow{2}{*}{0.035} \\
\hline No & $46(23.1)$ & $4(10.3)$ & $42(6.2)$ & \\
\hline \multicolumn{5}{|l|}{ Cardiopulmonary resuscitation } \\
\hline Yes & $17(8.5)$ & $8(20.5)$ & $9(5.6)$ & \multirow{2}{*}{0.007} \\
\hline No & $182(91.5)$ & $31(79.5)$ & $151(94.4)$ & \\
\hline \multicolumn{5}{|l|}{ ICU Time of Donor (days) } \\
\hline $0-7$ & $116(58.3)$ & $25(64.1)$ & $91(56.9)$ & \multirow{3}{*}{0.471} \\
\hline$>7$ & $83(41.7)$ & $14(35.9)$ & $69(43.1)$ & \\
\hline Warm ischemia time (min) & $16.2 \pm 5.2$ & & & \\
\hline$\leq 18 \min$ & $145(76.3)$ & $22(56.4)$ & $123(76.9)$ & \multirow{2}{*}{0.015} \\
\hline$>18 \min$ & $54(23.7)$ & $17(43.6)$ & $37(23.1)$ & \\
\hline
\end{tabular}

vs. $\leq 18 \mathrm{~min}=2.42 ; 95 \% \mathrm{CI}=1.36-4.32$ ).

To validate the clinical value of this model, independently analyzed data including 38 kidney transplants performed in The Third Affiliated Hospital of Sun Yat-sen University from January 2016 to January 2017 were used to plot the ROC determined by the final model. None of the patients used vasoactive drugs, and 2 had received CPR; 7 patients had WIT $>18 \mathrm{~min}$, and 31 had WIT $\leq 18 \mathrm{~min}$. A total of 34 patients had received ATG as induction therapy and 4 had received anti-interleukin-2 receptor antibody. Mean HLA mismatch was 2. Terminal serum creatinine was $168.7 \pm 112.9 \mu \mathrm{mol} / \mathrm{L}$, and mean body weight was $58.8 \pm 15.5$ kg. Of the 38 independent patients, 5 had DGF (13.2\%).

The AUC was 0.78 (95\% CI 0.61-0.90). Optimal operation point of this predictive model was 0.32 , with a sensitivity of $80.0 \%$ and a specificity of $81.8 \%$ (Fig. 1).

We combined our predicted factors with Irish's model to assess probability of DGF [4]. The combined prediction model demonstrated an AUC of 0.89 (95\% CI 0.75-0.97 0.61-0.90) compared with $0.75(0.59-0.88)$ and $0.78(0.61-0.90)$ for Irish's model and our prediction model, respectively (Fig. 2). 


\section{Kidney Blood Pressure Research}

Table 2. Recipient characteristics stratified by DGF. Cr, creatinine; PRA, panel-reactive antibody; HLA, human leukocyte antigen; DGF, delayed graft function

\begin{tabular}{|c|c|c|c|c|}
\hline Recipient characteristics & All patients, n (\%) & DGF, n (\%) & no-DGF, n (\%) & p-value \\
\hline Total & 383 & 74 & 309 & \\
\hline Age (years) & $42.5 \pm 11.1$ & & & \\
\hline \multicolumn{5}{|l|}{ Sex } \\
\hline Male & $239(62.4)$ & $46(62.2)$ & 193(62.5) & \\
\hline Female & 144(37.6) & $28(37.8)$ & $116(37.5)$ & 1 \\
\hline Preoperative $\mathrm{Cr}(\mu \mathrm{mol} / \mathrm{L})$ & $931.2 \pm 287.4$ & & & \\
\hline \multicolumn{5}{|l|}{ Previous transplants } \\
\hline First transplant & $374(97.7)$ & $70(94.6)$ & $304(98.4)$ & 0.075 \\
\hline Second transplant & $9(2.3)$ & $4(5.4)$ & $5(1.6)$ & \\
\hline \multicolumn{5}{|l|}{ PRA } \\
\hline Positive & $12(3.1)$ & $2(2.7)$ & $10(3.2)$ & \\
\hline Negative & $371(96.9)$ & $72(97.3)$ & $299(96.8)$ & 1 \\
\hline \multicolumn{5}{|l|}{ Induction therapy } \\
\hline Antithymocyte globulin & 291(76) & $25(33.8)$ & $266(86.1)$ & \\
\hline Anti-interleukin-2 receptor antibody & $92(24)$ & $49(66.2)$ & 43(13.9) & 0 \\
\hline \multicolumn{5}{|l|}{ HLA mismatches } \\
\hline Level 1 & $274(71.5)$ & $54(73)$ & $220(71.2)$ & \multirow{5}{*}{0.381} \\
\hline Level 2 & $79(20.6)$ & $12(16.2)$ & $67(21.7)$ & \\
\hline Level 3 & $30(7.9)$ & $8(10.8)$ & $22(7.1)$ & \\
\hline Pre-emptive dialysis vintage (years) & $1.3 \pm 1.0$ & & & \\
\hline Cold ischemia time $(\mathrm{h})$ & $5.5 \pm 2.2$ & & & \\
\hline$<6$ & $266(69.5)$ & $52(70.3)$ & 214(69.3) & \\
\hline $6-12$ & $110(28.7)$ & $20(27)$ & $90(29.1)$ & 0.785 \\
\hline$>12$ & $7(1.8)$ & $2(2.7)$ & $5(1.6)$ & \\
\hline
\end{tabular}

Table 3. Paired recipients received graft donations from same donors stratified by induction. Cr, creatinine; PRA, panel-reactive antibody; HLA, human leukocyte antigen; DGF, delayed graft function; AR, acute rejection

\begin{tabular}{|c|c|c|c|}
\hline Recipient characteristics (paired) & ATG & Anti-interleukin-2 receptor antibody & $\mathrm{p}$-value \\
\hline Total & $\mathrm{n}=25$ & $\mathrm{n}=25$ & \\
\hline Age (years) & $49 \pm 6.5$ & $47 \pm 8.6$ & 0.576 \\
\hline \multicolumn{4}{|l|}{ Sex } \\
\hline Male & 17 & 19 & \multirow{2}{*}{0.5} \\
\hline Female & 8 & 6 & \\
\hline Preoperative $\mathrm{Cr}(\mu \mathrm{mol} / \mathrm{L})$ & $1059.8 \pm 202.1$ & $866.8 \pm 144.5$ & 0.275 \\
\hline \multicolumn{4}{|l|}{ Previous transplants } \\
\hline First transplant & 24 & 25 & \multirow{3}{*}{0.5} \\
\hline Second transplant & 1 & 0 & \\
\hline \multicolumn{3}{|l|}{ PRA } & \\
\hline Positive & 0 & 1 & \multirow{2}{*}{0.5} \\
\hline Negative & 25 & 24 & \\
\hline \multicolumn{4}{|l|}{ HLA mismatches } \\
\hline Level 1 & 19 & 23 & \multirow{3}{*}{0.304} \\
\hline Level 2 & 3 & 1 & \\
\hline Level 3 & 3 & 1 & \\
\hline Pre-emptive dialysis vintage (years) & $1.4 \pm 1.3$ & $1.4 \pm 1.0$ & 0.925 \\
\hline \multicolumn{4}{|l|}{ Cold ischemia time $(\mathrm{h})$} \\
\hline$<6$ & 20 & 20 & \multirow{3}{*}{0.637} \\
\hline $6-12$ & 5 & 5 & \\
\hline$>12$ & 0 & 0 & \\
\hline \multicolumn{4}{|l|}{ Postoperative complications } \\
\hline DGF & 1 & 9 & 0.005 \\
\hline $\mathrm{AR}$ & 1 & 2 & 0.5 \\
\hline Complicated urinary tract infection & 1 & 2 & 0.5 \\
\hline Severe pneumonia & 5 & 2 & 0.209 \\
\hline Severe bleeding & 0 & 1 & 0.5 \\
\hline Renal allograft rupture & 1 & 0 & 0.5 \\
\hline Other & 0 & 4 & 0.055 \\
\hline
\end{tabular}




\section{Kidney \\ Blood Pressure Research}

Table 4. Results of the logistic regression analysis of delayed graft function. ATG, antithymocyte globulin

\begin{tabular}{lccccc}
\hline Variables & Estimate & Standard error & Sig & Odds ratio & $\begin{array}{c}95 \% \text { confidence interval } \\
\text { Lower }\end{array}$ \\
\hline Uecipient & & & & & \\
ATG used as induction therapy (yes vs. no) & -0.725 & 0.294 & 0.014 & 0.484 & 0.272 \\
Donor & & & & 0.862 \\
Use of vasoactive drugs (yes vs. no) & 1.146 & 0.418 & 0.006 & 3.145 & 1.386 \\
Cardiopulmonary resuscitation (yes vs. no) & 0.921 & 0.444 & 0.038 & 2.511 & 1.052 \\
Warm ischemia time (>18 vs. $\leq 18$ min) & 0.884 & 0.296 & 0.003 & 2.42 & 1.355 \\
\hline
\end{tabular}

Fig. 1. Predictive accuracy of the delayed graft function (DGF) model determined by receiver operating curve (ROC). The predictive accuracy of the DGF model was validated by use of data from brain death followed by circulatory death (DBCD) renal transplant recipients. The ROC shows considerable ability of the index to correctly classify DGF at varying levels of risk. The area under the ROCs (AUC) for the validation of the model using these data was 0.78 . The optimal operation point of this predictive model was 0.32 , with a sensitivity of $80 \%$ and specificity of $81.8 \%$.

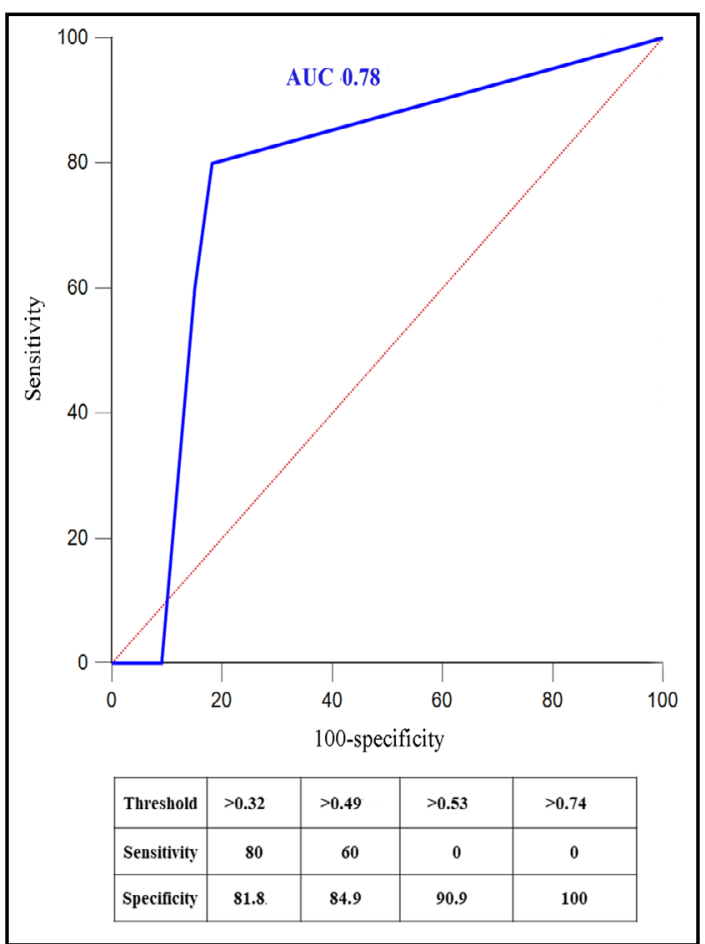

Fig. 2. Comparative analysis of ROCs for three prediction models of DGF. Our prediction model (blue curve), Irish's model (green curve), and the combination model of the two (red curve) were compared by ROC analysis, and the AUC of the combination model was 0.89 .

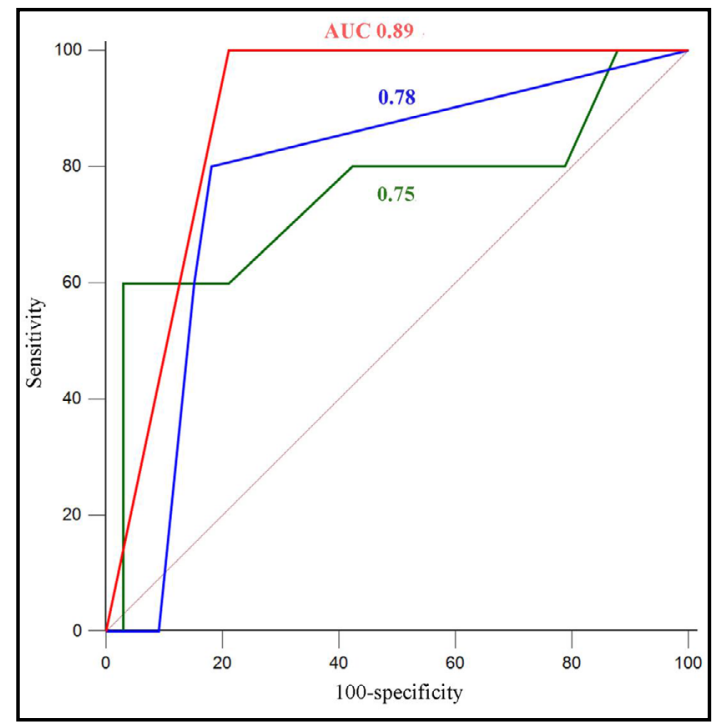




\section{Kidney Blood Pressure Research}

Kidney Blood Press Res 2018;43:893-903

\begin{tabular}{l|l}
\hline DOI: $10.1159 / 000490337$ & (C) 2018 The Author(s). Published by S. Karger AG, Basel
\end{tabular}

Published online: 5 June, 2018

www.karger.com/kbr

\section{Discussion}

This is the first multi-center study to explore factors associated with DGF in DBCD donation. We identified two novel parameters, use of vasoactive drugs and CPR in donors, as independent risk factors for DGF in kidney transplantation from DBCD donors. ATG as induction also proved to be an independent protective factor for DGF, with prolonged WIT also having predictive value for DGF. This predictive model of DGF in DBCD showed a good degree of discrimination when combined with current predictive parameters.

As novel independent risk factors of DGF, use of vasoactive drugs and CPR were useful to optimize donor management and improve graft outcomes. Our data showed that $89.7 \%$ and $20.5 \%$ of grafts developing DGF originated from donors that had used vasoactive drugs and had received CPR, respectively, which was significantly different from grafts without a history of vasoactive drug use or CPR. Use of vasoactive drugs and CPR in donors could increase DGF risk by 3.15- and 2.51-fold. Vasoactive drugs and CPR increase the incidence of DGF by causing widespread renal vascular sclerosis and glomerular sclerosis, which are themselves precursors of acute kidney injury and thus increase the incidence of DGF. It has been reported that repeated CPR could exert a more severe adverse effect on transplanted kidneys [18]. Furthermore, renal ischemia/reperfusion injury (IRI) mediated by vasoactive drugs and CPR could cause functional impairment through multiple factors, such as renal vasoconstriction, tubular obstruction, tubular back-leakage of glomerular filtrate, reduced glomerular permeability, and apoptosis, all of which inevitably exert adverse effects on DGF [19]. Generally, grafts may also be compromised by the use of vasoactive drugs and CPR in other donation classifications, so we considered that the two novel factors may also be suitable for predicting DGF in DCD and DBD, not just for DBCD. Hence, efforts to optimize vasoactive drug dose and frequency of CPR should be areas of further research.

ATG as induction therapy in DBCD can be recommended as a protective factor in DGF. In our study, the incidence of DGF in DBCD was just 19.3\%, similar to previous results in DBD [20]. We surmised that decreased DGF was associated with ATG as induction therapy. In another report, ATG has already been shown to decrease DGF risk [21-23]. A recent randomized trial showed that $31.5 \%$ of patients in an ATG group developed DGF compared with $44.6 \%$ using anti-interleukin 2 receptor antibody treatment. Chapal et al. also found five explicative variables that contributed significantly to DGF prediction, and demonstrated that risk of DGF was reduced 1.73-fold in patients with ATG [6]. Other studies also demonstrated significantly lower rates of DGF in ATG-induced DCD recipients [24-26]. Our results demonstrated that ATG as induction therapy in DBCD donation could reduce the risk of DGF by more than half. Furthermore, a matched group where paired recipients received graft donations from the same donors also confirmed this finding. The protective effect of ATG on the incidence of DGF may be attributed to limiting leukocyte activation, renal graft infiltration, and cytokine release, which are involved in tissue damage and early graft dysfunction. The use of calcineurin inhibitors was also delayed by ATG induction therapy, which was likely to have a positive impact on immediate graft function [27]. Moreover, significant differences were found in a primate model between ATG-treated and ATGfree groups concerning blood flow velocity, leukocyte count, and leukocyte-endothelium interaction after ischemia/reperfusion, which suggests that the protective effect of ATG may partly be due to these findings [28].

Consistent with other studies, our findings suggest that prolonged WIT was particularly detrimental to kidneys from DBCD donation, and was associated with a higher risk of DGF $[29,30]$. WIT of $>18 \mathrm{~min}$ increased DGF risk 2.42 -fold compared with $<18 \mathrm{~min}$. Prolonged WIT causes severe adverse events related to IRI and acute kidney injury, all of which inevitably adversely affect graft recovery and increase the risk of DGF $[21,22]$. However, in our study, the average WIT of kidney obtained from DBCD was limited to $16.2 \pm 5.2 \mathrm{~min}$, 


\section{Kidney Blood Pressure Research}

Sun et al.: Predicting DGF in DBCD

which was much lower than an average of 27 min through DCD [31]. The shorter WIT in DBCD contributes to reducing IRI and irreversible cell and tissue damage, and leads to better graft function recovery, which ultimately results in lower risk of DGF.

We combined our predictive factors with Irish's model to assess the probability of DGF and achieved an AUC of 0.89. Given that our predictive factors were different from those used in Irish's model, we suggest that the factors identified in our study can be used as riskpredicting parameters complementary to current DGF models in order to achieve greater accuracy and higher clinical value in predicting DGF.

As always for such observational studies, several limitations have to be underscored. Firstly, other confirmed predictive factors such as body mass index, duration of dialysis pretransplantation, longer CIT, and increasing donor age failed to be recognized in our study due to its insufficient size. Secondly, the 38 independent patients whose data were used to plot the ROC determined by the final model were from a single transplantation center. Therefore, further external validation is required in other institutions. Finally, the period of cardiopulmonary arrest requiring $\mathrm{CPR}$, and the dosage range of vasoactive drugs predisposing to DGF need to be further determined. Despite the high quality of this methodology, more parameters should be assessed to develop the prediction model in a further large-scale study.

\section{Conclusion}

Our study is the first to confirm that use of vasoactive drugs and CPR in donors were significantly associated with DGF in DBCD. Apart from the risk factors confirmed in DBCD donation, it may be also suitable for predicting DGF in DBD and DCD donation because of the universality of such risk factors. The predictive factors can be used as complementary parameters to achieve greater accuracy and higher clinical value based on the current predictive model.

\section{Acknowledgements}

This study was supported by grants from the National Natural Science Foundation of China (No. 81470978, 81279834, 81770753); Major Program of Science and Technology Planning Project of Guangdong Province, China (No. 2015B020226005); Key Project of Natural Science Foundation of Guangdong Province, China (No. 2015A030311040); Leading Scientific, Technical and Innovation Talents of Guangdong Special Support Program (No. 510204006192). Medical writing assistance was provided by Nucleus Global and ThinkSCIENCE, Inc. and funded by Sanofi China.

\section{Disclosure Statement}

The authors of this manuscript state that they do not have any conflicts of interest and have nothing to disclose.

\section{References}

\footnotetext{
1 Tonelli M, Wiebe N, Knoll G, Bello A, Browne S, Jadhav D, Klarenbach S, Gill J: Systematic review: kidney transplantation compared with dialysis in clinically relevant outcomes. Am J Transplant 2011;11:20932109.

2 Tapiawala SN, Tinckam KJ, Cardella CJ, Schiff J, Cattran DC, Cole EH, Kim SJ: Delayed graft function and the
} 


\section{Kidney \\ Blood Pressure Research}

\begin{tabular}{l}
\hline Kidney Blood Press Res 2018;43:893-903 \\
\begin{tabular}{l|l}
\hline DOI: 10.1159/000490337 & (c) 2018 The Author(s). Published by S. Karger AG, Basel \\
Published online: 5 June, 2018 & www.karger.com/kbr
\end{tabular}
\end{tabular}

Published online: 5 June, 2018 www.karger.com/kbr

Sun et al.: Predicting DGF in DBCD

risk for death with a functioning graft. J Am Soc Nephrol 2010;21:153-161.

- 3 Yarlagadda SG, Coca SG, Formica RN Jr., Poggio ED, Parikh CR: Association between delayed graft function and allograft and patient survival: a systematic review and meta-analysis. Nephrol Dial Transplant 2009;24:1039-1047.

-4 Irish WD, Ilsley JN, Schnitzler MA, Feng S, Brennan DC: A risk prediction model for delayed graft function in the current era of deceased donor renal transplantation. Am J Transplant: 2010;10:2279-2286.

-5 Irish WD, McCollum DA, Tesi RJ, Owen AB, Brennan DC, Bailly JE, Schnitzler MA: Nomogram for predicting the likelihood of delayed graft function in adult cadaveric renal transplant recipients. J Am Soc Nephrol 2003;14:2967-2974.

6 Chapal M, Le Borgne F, Legendre C, Kreis H, Mourad G, Garrigue V, Morelon E, Buron F, Rostaing L, Kamar N, Kessler M, Ladrière M, Soulillou JP, Launay K, Daguin P, Offredo L, Giral M, Foucher Y: A useful scoring system for the prediction and management of delayed graft function following kidney transplantation from cadaveric donors. Kidney Int 2014;86:1130-1139.

7 Basic-Jukic N, Gulin M, Hudolin T, Kastelan Z, Katalinic L, Coric M, Veda MV, Ivkovic V, Kes P, Jelakovic B: Expression of BMP-2 in Vascular Endothelial Cells of Recipient May Predict Delayed Graft Function After Renal Transplantation. Kidney Blood Press Res 2016;41:781-793.

8 Huang J, Wang H, Fan ST, Zhao B, Zhang Z, Hao L, Huo F, Liu Y: The national program for deceased organ donation in China. Transplantation 2013;96:5-9.

-9 Wu Z, Gao X, Chen F, Tao X, Cai J, Guo J, Chen X, Tan J, Yang S: Chinese Pediatric Organ Donation With Scheduled Cardiac Arrest After Brain Death: A Novel China Classification Beyond Maastricht. Transplant Proc 2015;47:2836-2840.

$>10$ Chinese Society of Organ Transplantation, Chinese Medical Association: National guidelines for donation after cardiac death in China. Hepatobiliary Pancreat Dis Int 2013;12:234-238.

11 Huang J, Millis JM, Mao Y, Millis MA, Sang X, Zhong S: A pilot programme of organ donation after cardiac death in China. Lancet 2012;379:862-865.

12 World Health Organization: Operational guidelines for ethics committees that review biomedical research. 2000. http://www.who.int/tdr/publications/ documents/ ethics. pdf?ua=1. Accessed December 2, 2016.

13 Beecher HK, Harvard Ad Hoc Committee: A definition of irreversible coma: report of the ad hoc committee of the Harvard Medical School to examine the definition of brain death. JAMA 1968;205:337-340.

14 Jochmans I, Darius T, Kuypers D, Monbaliu D, Goffin E, Mourad M, Ledinh H, Weekers L, Peeters P, Randon C, Bosmans JL, Roeyen G, Abramowicz D, Hoang AD, De Pauw L, Rahmel A, Squifflet JP, Pirenne J: Kidney donation after circulatory death in a country with a high number of brain dead donors: 10-year experience in Belgium. Transpl Int 2012;25:857-866.

15 Mallon DH, Summers DM, Bradley JA, Pettigrew GJ: Defining Delayed Graft Function after Renal Transplantation: Simplest Is Best. Transplantation 2013;96:885-889.

16 DeLong ER, DeLong DM, Clarke-Pearson DL: Comparing the areas under two or more correlated receiveroperating characteristic curves: a nonparametric approach. Biometrics 1988;44:837.

17 Wu Z, Gao X, Chen F, Tao X, Cai J, Guo J, Chen X, Tan J, Yang S: Chinese Pediatric Organ Donation With Scheduled Cardiac Arrest After Brain Death: A Novel China Classification Beyond Maastricht. Transplant Proc 2015;47:2836-2840.

18 Asher J, Navarro A, Watson J, Wilson C, Robson L, Gupta A, Gok M, Balupuri S, Shenton B, Del Rio Martin J, Sen B, Jaques B, Soomro N, Rix D, Manas D, Talbot D: Does donor cardiopulmonary resuscitation time affect outcome in uncontrolled non-heart-beating donor renal transplants? Transplant Proc 2005;37:3264-3265.

19 Hutchens MP, Nakano T, Kosaka Y, Dunlap J, Zhang W, Herson PS, Murphy SJ, Anderson S, Hurn PD: Estrogen is renoprotective via a nonreceptor-dependent mechanism after cardiac arrest in vivo. Anesthesiology 2010;112:395-405.

20 Summers DM, Watson CJ, Pettigrew GJ, Johnson RJ, Collett D, Neuberger JM, Bradley JA: Kidney donation after circulatory death (DCD): state of the art. Kidney Int 2015;88:241-249.

21 Schröppel B, Legendre C: Delayed kidney graft function: from mechanism to translation. Kidney Int 2014;86:251-258.

-22 Siedlecki A, Irish W, Brennan DC: Delayed graft function in the kidney transplant. Am J Transplant 


\section{Kidney \\ Blood Pressure Research}

Sun et al.: Predicting DGF in DBCD

2011;11:2279-2296.

23 Noël C, Abramowicz D, Durand D, Mourad G, Lang P, Kessler M, Charpentier B, Touchard G, Berthoux F, Merville P, Ouali N, Squifflet JP, Bayle F, Wissing KM, Hazzan M: Daclizumab versus antithymocyte globulin in high-immunological-risk renal transplant recipients. J Am Soc Nephrol 2009;20:1385-1392.

-24 Popat R, Syed A, Puliatti C, Cacciola R: Outcome and cost analysis of induction immunosuppression with IL2Mab or ATG in DCD kidney transplants. Transplantation 2014;97:1161-1165.

-25 Ulrich F, Niedzwiecki S, Pascher A, Kohler S, Weiss S, Fikatas P, Schumacher G, May G, Reinke P, Neuhaus P, Tullius SG, Pratschke J: Long-term outcome of ATG vs. Basiliximab induction. Eur J Clin Invest 2011;41:971978.

26 Chen G, Gu J, Qiu J, Wang C, Fei J, Deng S, Li J, Huang G, Fu Q Chen L: Efficacy and safety of thymoglobulin and basiliximab in kidney transplant patients at high risk for acute rejection and delayed graft function. Exp Clin Transplant 2013;11:310-314.

-27 Kamar N, Garrigue V, Karras A, Mourad G, Lefrançois N, Charpentier B, Legendre C, Rostaing L: Impact of early or delayed cyclosporine on delayed graft function in renal transplant recipients: a randomized, multicenter study. Am J Transplant 2006;6:1042-1048.

28 Chappell D, Beiras-Fernandez A, Hammer C, Thein E: In vivo visualization of the effect of polyclonal antithymocyte globulins on the microcirculation after ischemia/reperfusion in a primate model. Transplantation 2006;81:552-658.

29 Roodnat JI, Mulder PG, Van Riemsdijk IC, IJzermans JN, van Gelder T, Weimar W: Ischemia times and donor serum creatinine in relation to renal graft failure. Transplantation 2003;75:799-804.

-30 Tennankore KK, Kim SJ, Alwayn IP, Kiberd BA: Prolonged warm ischemia time is associated with graft failure and mortality after kidney transplantation. Kidney Int 2016;89:648-658.

-31 Nagaraja P, Roberts GW, Stephens M, Horvath S, Fialova J, Chavez R, Asderakis A, Kaposztas Z: Influence of delayed graft function and acute rejection on outcomes after kidney transplantation from donors after cardiac death. Transplantation 2012;94:1218-1223. 